\title{
KELUHAN KELELAHAN MATA PADA PEKERJA PENGGUNA KOMPUTER DI PERUSAHAAN TRAVEL DI KOLAKA RAYA
}

\author{
Sunyanti ${ }^{1}$ \\ ${ }^{1}$ Program Studi Ilmu Komputer Fakultas Teknologi Informasi \\ Universitas Sembilanbelas November Kolaka \\ E-mail: sunyantis@gmail.com/sun.fti@usn.ac.id
}

\begin{abstract}
ABSTRAK
Kelelahan mata pada pengguna komputer dapat terjadi karena bekerja dengan melihat dan membaca dekat dalam waktu yang lama. Kondisi demikian dapat menurunkan ketelitian dan kewaspadaan. Selain itu dapat menurunkan kondisi kesehatan pekerja bahkan dapat menyebabkan kecelakaan kerja. Oleh karena itu penelitian ini dilakukan untuk mengetahui keluhan kelelahan pada pekerja pengguna komputer di Perusahaan Travel di Kolaka Raya. Penelitian ini adalah penelitian kuantitatif dengan desain study cross sectional. Sampel penelitian ini adalah 30 pengguna komputer di Perusahaan Travel di Kolaka Raya. Pengambilan data dilakukan dengan menyebarkan kuesioner dan melakukan pengukuran jarak pandang antara mata dan layar komputer. Analisis Univariat dilakukan menggunakan nilai proporsi untuk menjelaskan gambaran keluhan kelelahan mata dan hubungan pada pengguna komputer dengan kelelahan mata, sedangkan analisis bivariat dilakukan dengan uji chi square $\left(\mathrm{X}^{2}\right)$ dengan tingkat kemaknaan $10 \%$. Hasil penelitian menunjukkan bahwa 22 responden atau 73,3\% mengalami keluhan kelelahan mata. Keluhan yang paling banyak yang di alami pekerja adalah sakit kepala sebanyak $(53,3 \%)$. Berdasarkan hasil uji statistik diketahui bahwa variabel yang berhubungan dengan keluhan kelelahan mata adalah variabel durasi kerja (Pvalue $=0,03)$. Untuk menurunkan risiko keluhan kelelahan mata pada pengguna komputer di sarankan perlu dilakukannya perawatan dan pemeliharaan terhadap kualitas pencahayaan dan pembersihan lampu secara berkala selama 6 bulan sekali. Perlu adanya sosialisasi terhadap karyawan terkait waktu istirahat yang tepat agar tidak menggunakan waktu istirahat untuk beraktivitas menggunakan komputer.
\end{abstract}

Kata Kunci: Keluhan Kelelahan Mata, Pengguna Komputer.

\begin{abstract}
Eye fatigue in computer users can occur because it works by seeing and reading near in a long time. Such conditions can decrease accuracy and alertness. In addition can reduce the health condition of workers can even cause accidents work. Therefore, this research is done to know the complaints of fatigue on workers computer users in the Travel company in Kolaka Raya. This research is quantitative research with a cross sectional study design. This research sample is 30 computer users in the Travel company in Kolaka Raya. Data retrieval is performed by spreading questionnaires and measuring visibility between eyes and computer screen. Univariat is done using a proportion value to explain the description of eye fatigue complaints and relationships in computer users with eye fatigue, bivariate analysis is performed with a Chi square test (X2) with a 10\% significance rate. The results showed that 22 respondents or
\end{abstract}


$73.3 \%$ had eye fatigue complaints. The most complaints that are in the natural worker are headaches as much as (53.3\%). Based on the results of a statistical test it is known that variables associated with eye fatigue complaints are variable duration work (Pvalue $=0.03$ ).

To reduce the risk of eye fatigue complaints on computer users in suggesting the need to do maintenance and maintenance to the quality of lighting and cleaning of the lamp periodically for 6 months. There is a need to socialize with the right resting time so as not to use the rest time to use the computer.

Keywords: Eye Fatigue Complaints, Computer Users.

\section{PENDAHULUAN}

Keselamatan dan Kesehatan kerja (K3) merupakan suatu program yang di dasari pendekatan ilmiah dalam upaya mencegah atau memperkecil terjadinya penyakit akibat kerja. Menurut Suma'mur (2001:104) keselamatan kerja merupakan suatu rangkaian usaha untuk menciptakan suasana kerja yang aman dan tentram bagi para karyawan yang bekerja di perusahaan yang bersangkutan. Kecelakaan kerja maupun kerugian-kerugian lainya yang mungkin terjadi. Saat ini K3 sudah menjadi perhatian di setiap aspek kehidupan, karena pada dasarnya kita tak pernah luput dari kondisi kerja yang berisiko. K3 pun makin menjadi perhatian karena pada dasarnya K3 merupakan hak asasi manusia. Tujuan dari K3 adalah menciptakan suasana kerja yang sehat dan aman bagi pekerja untuk mencegah kerugian baik material maupun non material.
Sesuai dengan namanya, keselamatan dan kesehatan kerja maka kesehatan kerja menjadi salah satu aspek penting dalam keselamatan dan kesehatan kerja. Hal tersebut di karenakan banyaknya bahaya atau hazard yang dapat mengganggu atau merusak kesehatan kerja. Pentingnya kesehatan kerja pun tertuang dalam Undang-Undang Kesehatan Republik Indonesia Nomor 36 Tahun 2009 Bab 12 yang khusus membahas tentang kesehatan kerja.

Pada dunia kerja, interaksi antara manusia, alat kerja, dan lingkungan kerja tidak dapat di hindarkan. Interaksi tersebutlah yang kerap kali mengakibatkan kecelakaan kerja atau penyakit akibat kerja. Salah satu contoh interaksi tersebut adalah interaksi antara mata (anggota tubuh), komputer dan suhu udara (lingkungan kerja).

Setiap pekerjaan didepan komputer akan mengakibatkan kelelahan, mata kering dan pegal. 
Oleh sebab itu beban kerja dan waktu kerja harus seimbang supaya tidak menimbulkan kelelahan mata pada pengguna komputer. Adanya keluhan dikarenakan tingkat lembur yang tinggi yang diberlakukan sehingga tak jarang karyawan merasa kelelahan akibat jam kerja yang berlebihan otomatis juga akan mengganggu kesehatan mata pada pengguna komputer. Bahwa dilihat dari perspektif energi radiasi dapat dikatakan radiasi komputer, yaitu yang dapat dikelompokkan dengan sinar non pengionan, tetapi dimana sinar tersebut tidak tampak menimbulkan efek berbahaya secara langsung bagi manusia. Namun harus diperhatikan lamanya radiasi menyinari tubuh, khususnya mata. Intesitas yang rendah tapi dalam waktu yang lama bisa menimbulkan gangguan fisiologis seperti merasa gelisah dan tidak nyaman sehingga mengganggu konsentrasi karyawan sewaktu bekerja.

Mata merupakan bagian tubuh pekerja yang harus dilindungi keselamatan dan kesehatannya. Dengan mata, setiap pekerja dapat melihat objek yang ada di sekitarnya dan melakukan berbagai macam pekerjaan. Hampir setiap pekerjaan melibatkan panca indera yang satu ini.Untuk itu sangat di perlukan penglihatan yang baik dalam setiap pekerjaan agar mendapatkan hasil yang maksimal.
Komputer adalah suatu alat elektronika yang digunakan untuk mengetik, mendesign, atau menciptakan karya - karya lain dalam bentuk soft file. Menurut Oetomo adalah suatu alat elektronika yang bekerja secara otomatis, terintegrasi, dan terkoordinasi sehingga dengan prosedur tertentu, (baik masukan atau hasil proses) dan menampilkan hasil proses tersebut (Oetomo, 2006). Pengunaan komputer sangat penting dan tidak dapat dipisahkan dari kehidupan modern seperti sekarang ini. Makin seringnya para pekerja bekerja dengan komputer maka makin besar kemungkinan para pekerja mengalami keluhan kelelahan mata.

Penggunaan komputer dewasa ini telah demikian luas di segala bidang, baik di perkantoran maupun bagian dari kehidupan pribadi seseorang. Hampir semua petugas administrasi menggunakan komputer dalam pekerjaan sehari-hari. Pengguna komputer tidak terlepas dari hal-hal yang dapat mengganggu kesehatan (Roestijawati, 2007).

Salah satu jenis pekerjaan yang secara kontinyu menggunakan komputer adalah karyawan biro perjalanan atau travel. Secara umum karyawan biro perjalanan bekerja di depan komputer untuk melayani pemesanan tiket perjalanan khususnya pada biro perjalanan pesawat udara, sehingga berisiko terhadap 
radiasi medan magnetik non peng-ion yang di hasilkan komputer melalui layar monitor maupun peralatan komputer lainnya.

Menurut Firdaus, 2003 menyatakan bahwa kelelahan mata dapat menurunkan produktivitas kerja dikarenakan pekerja mengalami berbagai keluhan yang menyebabkan hilangnya konsentrasi dan menurunkan semangat kerja. Kondisi demikian cenderung akan menurunkan ketelitian dan lebih lanjut dapat menyebabkan terjadinya keselahan, memperpanjang waktu kerja, menurunkan produksi, di samping itu juga dapat menurunkan kewaspadaan dan cenderung terjadinya kecelakaan kerja atau menambah angka kecelakaan, serta mempengaruhi moral kerja (Soeripto, 2008).

Dari hasil studi sebelumnya (Carayon, 1995 dalam Sundari 2011) bahwa pengguna komputer apabila bekerja terlalu lama di depan komputer akan mengalami beberapa keluhan. Keluhan yang dapat di timbulkan karena pemakaian komputer adalah keluhan kelelahan mata sebanyak 75\%-90\% dan keluhan musculoskeletal porsinya hanya $22 \%$. Untuk itu peneliti tertarik melakukan penelitian mengenai keluhan kelelahan mata pada pekerja pengguna komputer di perusahaan travel di Kolaka Raya.
Untuk itu yang mejadi tujuan dari penelitian ini adalah untuk mengetahui gambaran keluhan kelelahan mata, mengetahui gambaran karakteristik pekerja (umur dan gangguan penglihatan), mengetahui gambaran karakteristik pekerjaan seperti durasi kerja, mengetahui hubungan faktor perangkat kerja yaitu (jarak pandang dan tampilan layar monitor) dengan kelelahan mata, mengetahui hubungan faktor lingkungan kerja yaitu Suhu udara dan pencahayaan dengan kelelahan mata pada pengguna komputer di perusahaan travel di Kolaka Raya.

\section{METODE PENELITIAN}

Penelitian ini merupakan penelitian kuantitatif dengan menggunakan study cross sectional, suatu metode penelitian yang dilakukan dengan tujuan utama membuat gambaran atau deskripsi tentang suatu penerapan secara objektif (Sugiyono, 2012). Hal ini dikarenakan penulis ingin melihat gambaran keluhan kelelahan mata pada pengguna komputer di perusahaan travel di Kolaka Raya dan Selain itu penulis ingin melihat antara hubungan antara karakteristik pekerja, durasi kerja, kondisi perangkat kerja, dan kondisi lingkungan kerja dengan keluhan kelelahan mata. 


\section{HASIL DAN PEMBAHASAN}

\section{Hubungan antara usia dan kelelahan mata}

Berdasarkan hasil penelitian, didapatkan jumlah pekerja yang berusia lebih 30 tahun sebanyak 21 pekerja dan pekerja yang berusia kurang lebih 30 tahun sebanyak 9 pekerja dari proporsi tersebut dapat dilihat bahwa persentase pekerja yang berusia lebih 30 tahun sebanyak 81,0\% (17 dari 21 pekerja) yang mengalami keluhan kelelahan mata di banding pekerja yang berumur kurang dari 30 tahun sebanyak 55,6\% (5 dari 9 pekerja) yang mengalami keluhan kelelahan mata. Hasil uji statistik menyatakan bahwa ada hubungan yang signifikan antara Usia dengan keluhan kelelahan mata yang ditunjukkan dengan nilai Pvalue sebesar 0,195. Lebih lanjut Ilyas, 2006 mengungkapkan seseorang sulit melihat pada jarak dekat biasanya terjadi pada usia 40 tahun. Pada usia ini, seseorang yang melihat jarak baca $25 \mathrm{~cm}$ akan menggunakan akomodasi maksimal sehingga lebih cepat mengalami kelelahan mata.

\section{Hubungan antara gangguan penglihatan dan kelelahan mata}

Berdasarkan hasil penelitian, didapatkan jumlah pekerja yang mengalami gangguan penglihatan sebanyak 11 pekerja dan tidak mengalami gangguan penglihatan sebanyak 19 pekerja. Persentase pekerja dengan gangguan penglihatan dan mengalami keluhan kelelahan mata sebesar 81,8\% (9 dari 11 pekerja). Nilai ini lebih besar daripada persentase pekerja tanpa gangguan penglihatan dan mengalami keluhan kelelahan mata sebesar 63,3\% (13 dari 19 pekerja). Hasil uji statistik menunjukkan nilai Pvalue sebesar 0,672, hal ini berarti bahwa tidak ada hubungan yang signifikan antara gangguan penglihatan dengan keluhan kelelahan mata. Fauzia, 2004 mengatakan pengguna komputer yang tidak memiliki kelainan refraksi dapat mengalami kelainan refraksi yang berupa miopi sementara. Miopi sementara terjadi karena mata penguna komputer harus berakomodasi terus menerus yang menyebabkan pergeseran diafragma iris lensa ke arah depan dan mengakibatkan spasme otot-otot siliar. Sehingga dibutuhkan waktu pemulihan yang lebih panjang untuk kembali ke posisi diafragma semula. Hasil penelitian ini juga sejalan dengan penelitian yang dilakukan oleh Nakaishi dan Yamada, 1999. Lebih lanjut Bhanderi et al, 2008 menunjukkan adanya hubungan yang signifikan antara gangguan penglihatan dengan kelelahan mata.

\section{Hubungan antara durasi kerja dan kelelahan mata}


Berdasarkan hasil penelitian, didapatkan jumlah pekerja dengan durasi kerja lebih dari 8 jam sebanyak 19 pekerja dan dengan durasi kurang dari 8 jam sebanyak 11 pekerja. Persentase pekerja dengan durasi kerja lebih dari 8 jam dan mengalami keluhan kelelahan mata sebesar 73,7\% (14 dari 19 pekerja) sedangkan untuk pekerja yang bekerja dengan durasi kerja kurang dari 8 jam dan mengalami keluhan kelelahan mata sebesar 72,7\% (8 dari 11 pekerja). Hasil uji statistik menunjukkan niali Pvalue 0,03 maka dapat di simpulkan bahwa ada hubungan yang signifikan antara durasi kerja dengan keluhan kelelahan mata. Terdapat beberapa penelitian yang berhasil membuktikkan adanya hubungan durasi kerja dengan keluhan kelelahan mata. Para karyawan sebaiknya tidak menjadikan bekerja lebih dari 8 jam perhari sebagai suatu kebiasaan dan sebisa mungkin tidak bekerja lebih dari 8 jam perhari. Selain itu pengguna komputer sebaiknya memperhatikan waktu istirahat mereka dan jangan menggunakan waktu istrahat untuk melakukan aktifitas dengan komputer. Pihak perusahaan juga sebaiknya melakukan sosialisasi terkait istirahat dan peregangan yang perlu dilakukan oleh karyawan di tengah-tengah penggunaan komputer.

\section{Hubungan antara tampilan layar monitor dengan kelelahan mata}

Dari hasil penelitian ini, didapatkan jumlah pekerja dengan tampilan layar monitor yang dikategorikan baik sebanyak 20 pekerja dan dengan tampilan layar monitor yang dikategorikan buruk sebanyak 10 pekerja. Persentase pekerja dengan tampilan layar yang dikategorikan baik dan mengalami keluhan kelelahan mata sebesar 80,0\% (16 dari 20 pekerja), nilai ini lebih besar di bandingkan persentase pekerja dengan tampilan layar monitor dikategorikan buruk dan mengalami keluhan kelelahan mata sebesar 60,0\% (6 dari 10 pekerja). Hasil nilai uji statistik menunjukkan nilai Pvalue 0,384 maka dapat disimpulkan bahwa tidak ada hubungan yang signifikan antara tampilan layar monitor dengan keluhan kelelahan mata. Perbedaan hasil ini bisa jadi disebabkan karena proporsi kerja dengan tampilan monitor buruk jauh lebih sedikit dibandingkan pekerja dengan tampilan monitor baik (8 berbanding 22). Meskipun penelitian ini tidak berhasil membuktikan adanya hubungan yang signifikan antara tampilan monitor dengan keluhan kelelahan mata, alangkah baiknya bila pengguna komputer lebih memperhatikan tampilan monitornya dan mengaturnya agar lebih nyaman di gunakan. Apabila ada tampilantampilan yang mengganggu seperti terlalu suram, tampilan atau gambar kabur, monitor 
berkedip-kedip, silau, terlalu kecil (font huruf, gambar, icon) dan sulit dibaca segera ditanggulangi dan jangan dibiarkan berlarutlarut.

\section{Hubungan antara jarak pandang dengan kelelahan mata}

Dari hasil penelitian ini, didapatkan jumlah pekerja dengan jarak pandang $<50 \mathrm{~cm}$ sebanyak 7 pekerja dan dengan jarak pandang $>50 \mathrm{~cm}$ sebanyak 23. Persentase pekerja dengan jarak pandang $<50 \mathrm{~cm}$ dan mengalami keluhan kelelahan mata sebanyak 85,7\% (6 dari 7 pekerja), nilai ini lebih besar di bandingkan persentase kerja dengan jarak pandang $>50 \mathrm{~cm}$ dan mengalami keluhan kelelahan mata sebesar 69,6\% (16 dari 23 pekerja). Berdasarkan hasil penelitian, rata-rata para pekerja di perusahaan travel di Kolaka Raya bekerja jarak pandang 57 $\mathrm{cm}$. Hasil nilai uji statistik menunjukkan nilai Pvalue 0,683 maka dapat disimpulkan bahwa tidak ada hubungan yang signifikan antara jarak pandang dengan keluhan kelelahan mata. Hasil penelitian ini tidak selaras dengan penelitian oleh Jaschinski Kruza, dalam Bridger, 2003 yang menunjukkan bahwa pekerja sehat dan tidak mengeluhkan kelelahan mata ketika bebas untuk mengatur jarak pandang mereka sendiri yaitu jarak antara $51 \mathrm{~cm}$ sampai dengan $99 \mathrm{~cm}$. Hal ini mungkin disebabkan karena pengguna komputer yang bekerja dengan jarak pandang $>50 \mathrm{~cm}$ dan mengalami keluhan mata terjadi karena adanya faktor pencahayaan yang kurang sehingga tetap mengalami keluhan kelelahan mata. Selain pencahayaan yang optimal, seharusnya perusahaan memberikan informasi mengenai postur ergonomis ketika bekerja menggunakan komputer karena berdasarkan observasi yang peneliti lakukan, para pekerja tidak tahu mengenai postur ergonomis ketika bekerja.

\section{Hubungan antara pencahayaan dengan kelelahan mata}

Dari hasil penelitian ini, didapatkan jumlah pekerja yang pencahayaannya di kategorikan buruk sebanyak 14 pekerja dan dengan pencahayaannya di kategorikan baik sebanyak 16 pekerja. Persentase kerja yang pencahayaannya di kategorikan buruk dan mengalami keluhan kelelahan mata sebesar 78,6\% (11 dari 14 pekerja), nilai ini lebih kecil dibandingkan persentase pekerja yang pencahayaannya dikategorikan baik dan mengalami keluhan kelelahan mata sebesar 68,8\% (11 dari 16 pekerja). Hasil nilai uji statistik menunjukkan nilai Pvalue 0,689 maka dapat disimpulkan bahwa tidak ada hubungan yang signifikan antara pencahayaan dengan keluhan kelelahan mata. Soeripto, (2008) 
menjelaskan bahwa apabila intesitas pencahayaan tidak memadai (suram atau menyilaukan), maka dapat menyebabkan produktivitas tenaga kerja turun atau menjadi rendah. Standar pencahayaan yang sesuai dengan keputusan menteri Kesehatan Nomor 1405 tahun 2002 tentang persyaratan kesehatan lingkungan kerja perkantoran dan industri, bahwa untuk pekerjaan yang menggunakan komputer membutuhkan tingkat pencahayaan minimal 500 lux.

\section{Hubungan antara suhu udara dengan kelelahan mata}

Dari hasil penelitian ini, didapatkan jumlah pekerja yang suhu udara yang dikategorikan baik sebanyak 21 pekerja dan dengan suhu udara di kategorikan buruk sebanyak 8 pekerja. Persentase pekerja yang suhu udara di kategorikan baik dan menagalami keluhan kelelahan mata sebesar 66,7\% (14 dari 21 pekerja), nilai ini lebih kecil di bandingkan persentase yang suhu udara di kategorikan buruk dan mengalami kelelahan mata sebesar $88,9 \% \quad(8 \quad$ dari 9 pekerja). Hasil nilai uji statistik menunjukkan nilai Pvalue 0,374 maka dapat disimpulkan bahwa tidak ada hubungan yang signifikan antara Suhu Udara dengan keluhan kelelahan mata. Bagi orang Indonesia Suhu Udara yang dirasa nyaman adalah berada diantara antara 24 ${ }^{0} \mathrm{C}-26{ }^{0} \mathrm{C}$.

\section{KESIMPULAN}

Berdasarkan pada hasil penelitian dan analisis data terhadap hasil-hasil penelitian sebagai output dari pengumpulan dan pengolahan data sebagaimana yang telah diuraikan pada bab sebelumnya, maka pada bab ini dapat ditarik beberapa kesimpulan sebagai berikut :

1. Berdasarkan hasil penelitian terhadap karekteristik pekerja, didapatkan gambaran sebagai berikut.

a. Karyawan dengan usia lebih dari 30 tahun berjumlah 21 pekerja $(70,0 \%)$ dan karyawan dengan usia kurang lebih dari 30 tahun berjumlah 9 pekerja $(30,0 \%)$.

b. Karyawan dengan gangguan penglihatan berjumlah 11 pekerja $(36,7 \%)$ dan karyawan tanpa gangguan penglihatan berjumlah 19 pekerja $(63,3 \%)$.

2. Berdasarkan hasil penelitian terhadap durasi kerja disimpulkan bahwa karyawan dengan durasi kerja lebih dari 8 jam berjumlah 19 pekerja $(63,3 \%)$ dan karyawan dengan durasi kurang dari 8 jam berjumlah 11 pekerja $(36,7 \%)$. 
3. Berdasarkan hasil penelitian terhadap perangkat kerja, didapatkan gambar sebagai berikut:

a. Karyawan dengan tampilan monitor yang buruk berjumlah 10 pekerja $(33,3 \%)$ dan karyawan dengan tampilan yang baik berjumlah 20 pekerja $(66,7 \%)$.

b. Karyawan dengan jarak pandang $<50 \mathrm{~cm}$ berjumlah $7(23,3 \%)$ dan karyawan dengan jarak pandang $>50 \mathrm{~cm}$ berjumlah $23(76,7 \%)$.

4. Berdasarkan hasil penelitian terhadap lingkungan kerja didapatkan gambar sebagai berikut:

a. Karyawan dengan tingkat pencahayaan buruk berjumlah $14 \quad(46,7 \%)$ dan karyawan dengan tingkat pencahayaan baik berjumlah $16(53,3 \%)$.

b. Karyawan dengan Suhu Udara yang buruk berjumlah 9 (30,0\%) dan karyawan dengan Suhu Udara yang baik berjumlah $21(70,0 \%)$.

5. Berdasarkan hasil penelitian terhadap keluhan kelelahan mata terhadap pengguna komputer di perusahaan travel di Kolaka Raya di simpulkan bahwa karyawan mengalami keluhan kelelahan mata berjumlah 22 pekerja $(73,3 \%)$ dan karyawan tanpa keluhan kelelahan mata berjumlah 8 pekerja $(26,7 \%)$.
6. Berdasarkan hasil analisis terdapat berhubungan yang signifikan antara durasi kerja dengan keluhan kelelahan mata.

\section{DAFTAR PUSTAKA}

Ankrum, R, Dennis, CIE.1996. Eyestrain and Computer Monitor Viewing Distance. Nova Solation, Inc.

Bhanderi, Dinesh J. 2008. A Community based Study Of Asthenopia In Computer. Indian Jurnal of Opthamology.

Bridger. R,S. 2003. Introductions to Ergonomics, $2^{\text {nd }}$ Edition. London: Tylor and Francis.

Departemen Kesehatan RI. 1990. Upaya Kesehatan Kerja Sektor Informal di Indonesia. Jakarta: Departemen Kesehatan.

Fauzia, Irawaty. 2004. Upaya untuk mengurangi keluhan kelelahan mata yang menggunakan komputer di rumah sakit X Jakarta tahun 2013. Tesis. Fakultas Kedokteran. Universitas Indonesia. Jakarta.

Fauzi, Ahmad. 2006. Penyakit kibat kerja karena penggunaan komputer. Bagian ilmu Kesehatan Masyarakat dan Kedokteran Komunitas Lampung.

Firdaus, Fikri. 2013. Analisis Faktor Risiko Ergonomi Terhadap munculnya kelelahan mata pada tenaga kerja computer Vision Syndrom (CVS) pada pekerja pengguna computer yang berkacamata dan pekerja yang tidak berkacamata di PT X tahun 2013. Tesis. Fakultas Kesehatan Masyarakat. Universitas Indonesia. Depok. 
Grandjean, E. 2003. Ergonomics in Computerized offices. London: Taylor and Francis.

ILO. 2000. Pedoman Praktis Ergonomik. Tim Peterjemah Dewan K3 nasional. Jenewa Ilyas, Sidarta. 2004. Ilmu Penyakit Mata. Edisi ke-3. Jakarta: Balai Penerbit FKUI

Ilyas, Sidarta. 2005. Penuntun Ilmu Penyakit Mata. Edisi ke-3. Jakarta: Balai Penerbit FKUI.

Ilyas, Sidarta. 2006. Kelainan Refraksi dan Kacamata. Edisi ke-2. Jakarta: Balai Penerbit FKUI.

Ivone, July. 2004. "Hubungan Kelelahan Mata dengan Produktivitas Tenaga Kerja di bagian inspeksi Perusahaan Tekstil PT. X, Bandung". Tesis. Fakultas Kedokteran. Universitas Indonesia. Depok

Kevin Patton dan Gary Thibodeau. 2010. Anthony's Textbook Of Anatomy 7 physiology, $19^{\text {th }}$ Edition. Mosbie Elsevier. United States of America.

Maryamah, Siti. 2011. "Faktor - Faktor yang berhubungan dengan Keluhan Kelelahan Mata pada Pengguna Komputer di Bagian Outbound Call Graha Telkom BSD (Bumi Serpong Damai) Tangerang tahun 2011". Skripsi. Fakultas Kedokteran dan Ilmu Kesehatan. Universitas Islam Negeri (UIN) Syarif Hidayatullah, Jakarta.

Notoatmodjo, Soekidjo. 2003. Ilmu Kesehatan Masyarakat, prinsip- prinsip dasar cetakan ke 2. Jakarta: Rineka Cipta

Oborne, David J. 1995. Ergonomics at Work: Human Factors in Design and Development Edisi Ke- 3. Chichester: John Wiley \& Sons Ltd.
Oetomo, Budi S.D. 2006. Perencanaan \& Pengembangan Sistem Informasi. CV. Andi Offset (Penerbit Andi) Yogyakarta.

Pheasant, Stephen. 1991. Ergonomic Work and Health. Aspen Publisher Inc. Maryland USA.

Purnomo, Hari. 2004. Pengantar Teknik Industri Edisi II. Yogyakarta: Graha Ilmu.

Roestijawati, Nendyah. 2007. Sindrom Dry Eye pada Pengguna Visual Display Terminal (VDT). Cermin Dunia Kedokteran No. 154 available from

Soeripto, M. 2008. Higiene Industri. Jakarta. Balai Penerbit FKUI.

Santoso. 1985. Higiene Perusahaan (Panas). Program D3 Hiperkes dan KesKer UI.

Tylor \& Francis. 1997. The Effect of Fatigue on Vision. Available From.

Ziefle, Martina. 2001. 'Aging, Visual Performance and Eyestrain in Different Screen Technologies'. Human Factors and Ergonomics Society. 